\title{
Bannayan-Riley-Ruvalcaba Syndrome, Rare Etiology of Intestinal Hamartomatouspolyposis: A case report
}

\author{
ZANNATUL FERDOUS SONIA ${ }^{1}$, MD. RUKUNUZZAMAN ${ }^{2}$, ASM BAZLUL KARIM ${ }^{3}$, AFSANA YASMIN $^{4}$, \\ SHASHI BHUSHAN THAKUR ${ }^{4}$
}

\begin{abstract}
:
Bannayan-Riley-Ruvalcaba syndrome (BRRS) is a rare autosomal dominant congenital disorder, characterized bymacrocephaly, lipomas, hamartomas, and pigmented macule in genitalia. Several dozen cases have been reported in the medical literature, but no case has been reported in Bangladesh. We report a case of BRRS in a 11-year-old male child with recurrent per rectal bleeding with hamartomatouscolonic polyposis \& multiple subcutaneous lipomas on the anterior abdominal wall.In addition, patient had macrocephaly, intellectual impairment.Bleeding polyps were removed by colonoscopic polypectomy.
\end{abstract}

Key words: Bannayan-Riley-Ruvalcaba, per rectal bleeding, polyposis.

\section{Introduction:}

Bannayan-Riley-Ruvalcaba syndrome (BRRS) is a rare autosomal dominant disordermanifested with macrocephaly, hemangiomas, lipoma, hamartomatous intestinal polyposis, developmental delay and speckled pigmented maculae on the male genitalia ${ }^{1,2}$.The prevalence of BRRS is yet unknown. The disorder is under-diagnosed due to various signs andsymptoms and some of them are subtle. The disorder may be associated with mutation in tumor suppression gene (PTEN). In case of PTEN genemutation Cancer surveillance is recommended ${ }^{3}$. We report this rare syndrome in a 11-year-oldmale child with symptoms of recurrent lower gastro intestinal bleeding due to colonic polyp.

\section{Case report:}

Dihan 11-year old boy $1^{\text {st }}$ issue of nonconsanguineous parents admitted with the complaints of per rectal

1. Department of Pediatric Gastroenterology \& Nutrition, Bangabandhu Sheikh Mujib Medical University, Dhaka, Bangladesh.

2. Associate Professor, Department of Pediatric Gastroenterology \& Nutrition, Bangabandhu Sheikh Mujib Medical University, Dhaka, Bangladesh.

3. Chairman, Department of Pediatric Gastroenterology \& Nutrition, Bangabandhu Sheikh Mujib Medical University, Dhaka, Bangladesh.

4. Resident (Phase B), Department of Pediatric Gastroenterology \& Nutrition, Bangabandhu Sheikh Mujib Medical University, Dhaka, Bangladesh.

Correspondence: Dr. Zannatul Ferdous Sonia, Department of Pediatric Gastroenterology \& Nutrition, Bangabandhu Sheikh Mujib Medical University, Dhaka, Bangladesh. Mob: 8801715110801, E-mail: zannatulsonia134@gmail.com

Received: $14-12-2017$

Accepted: 14-03-2019 bleeding for 3 months. Bleeding was intermittent, small in amount, painless, bright red drops of blood after defecation. He had h/o of polypectomy. Seven days after polypectomy bleeding restarted with same character.Patient had no historyof fever, abdominal pain, joint pain, constipation, rash, abnormal bleeding tendency, visual disturbances. He had no family h/o of such type of illness. He was delivered by LUCS with birth weight of $5 \mathrm{~kg}$. He had h/o of delayed milestone of development. General physical examination revealed mild pallor, normal oral cavity. There was no jaundice, cyanosis, edema, thyromegaly, lymphadenopathy, clubbing, or scoliosis. Vitals within normal limit. Skin survey normal. Anthropometric examination revealed macrocephaly with head circumference of $59 \mathrm{~cm}$ ( $>97$ percentile), height $139 \mathrm{~cm}$ (on $25^{\text {th }}$ centile), weight $26 \mathrm{~kg}$ (between $5^{\text {th }} \& 3^{\text {rd }}$ centile (Figure 1). Multiple subcutaneous masses were present on the left lower abdomen measuring about $11 \mathrm{~cm} \times 9 \mathrm{~cm}$, soft in consistency (Figure 2). Other systemic examination revealed normal findings. Hematological and biochemical parameters were within normal limit. Colonoscopy revealed polyp in transverse colon (Figure 3) \& histopathology showed cystically dilated glands with chronic inflammation, features were consistent with hamartomatous polyp(Figure 4). Patient also had intellectual impairment on WISK-R assessment. There is cryptorchidism on genitalia examination. 


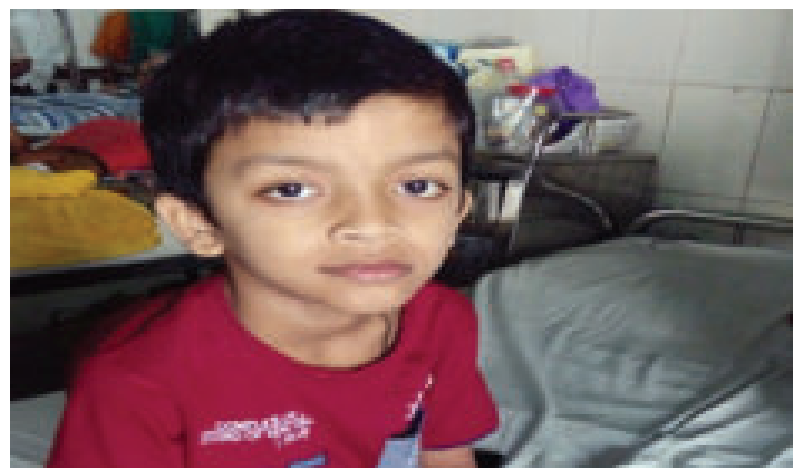

Fig.-1: Macrocephaly of presented case

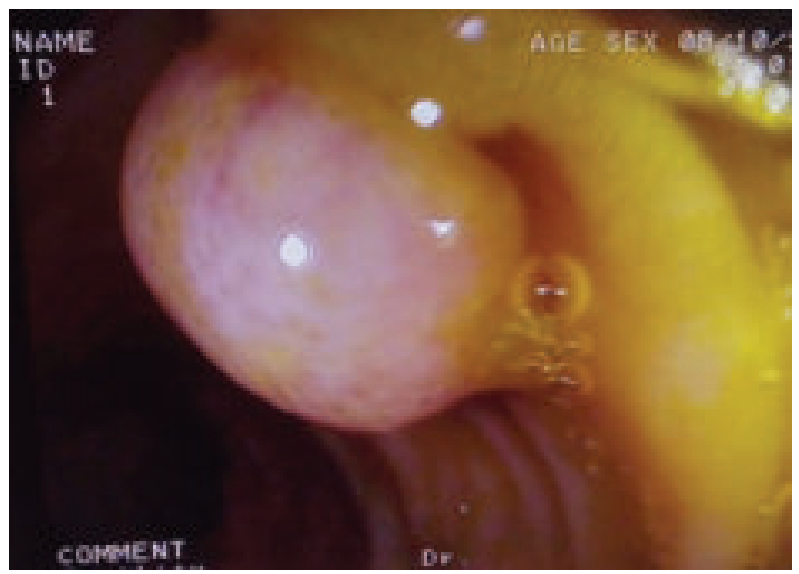

Fig.-3: Colonoscopy shows polyps in transverse colon

On the basis of clinical features of macrocephaly, lipomas, intellectual impairment, cryptorchidism and intestinal hamartomatous polyp; a diagnosis of Bannayan-Rilay-Ruvalcaba Syndrome (BRRS) was made. PTEN gene mutation analysis could not be done.

\section{Discussion:}

Bannayan-Riley-Ruvalcaba syndrome (BRRS) is a rare hamartomatous polyposis syndrome. This syndrome was originally described separately by Riley and Smith, Bannayan and Zonana, and Ruvalcaba, Myher, and Smith ${ }^{4}$. In 1990, Cohen used term BRRS to unify these as a single entity. DiLiberti proposed a new nomenclature of multiple syndromes that are caused by mutations in the PTEN gene. He proposed that it be called the PTEN MATCHS syndrome; MATCHS was derived from macrocephaly, autosomal dominant, thyroid disease, cancer, hamartomata, and skin abnormalities. Marsh et al. (1999) suggested that the spectrum of disorders maybe known as PTEN hamartoma tumor syndrome (PHTS).

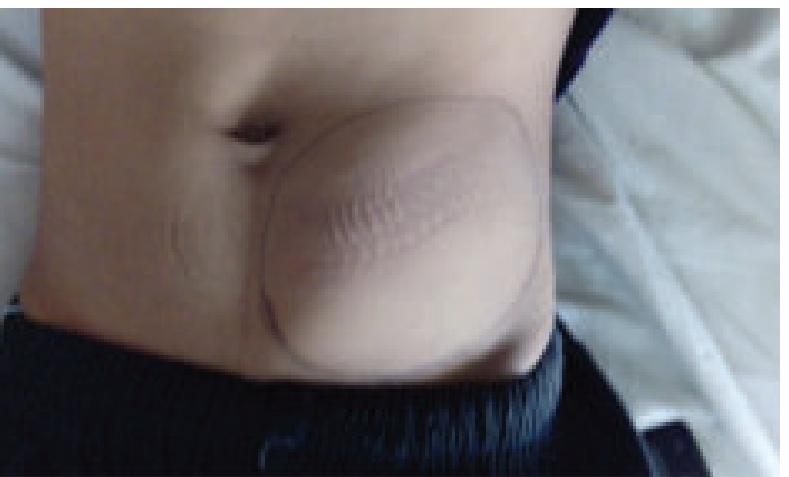

Fig.-2: Subcutaneous lipoma in abdomen

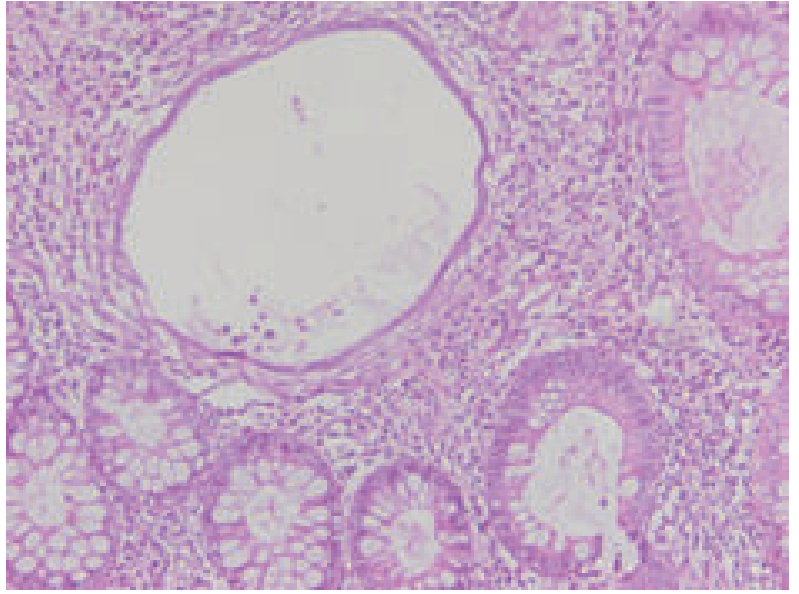

Fig.-4: H\& Ex200 shows juvenile polyp

It occurs both in an autosomal dominant and ina sporadic manner ${ }^{1}$. It occurs throughmutations in the phosphatase and the tensin homolog gene(PTEN) located on chromosome10q23.Germline mutations of (PTEN) gene are found in approximately $60 \%$ of $\mathrm{BRRs}^{5}$. This is a tumour suppressor gene that plays animportant role in the pathway of cell proliferation, migration and apoptosis. PTEN mutations are responsible for PTEN hamartoma tumor syndromes (PHTS), a group of diseases including, Cowden syndrome (CS), BRRS, PTEN-related Proteus syndrome, Proteus-like syndrome. PHTS are significant because of their predisposition to cancer.

BRRS is characterized by macrocephaly, lipomas, hemangiomas, hamartomatous intestinal polyps and pigmented macules in the genital region ${ }^{6}$. It is a rare disorder, several dozen case reportshad been reported in medical literature. The symptoms can either be present at birth or shows up during early childhood. Symptoms generally vary from one patient to another. Males are affected more often than females. Majority of infants have increased birth 
weight and length and about half of affected infants have macrocephaly without enlargement of ventricles. Growth usually slows during childhood, so affected adults are of normal height and body size. There may be a delay. In developmental milestones and low intelligence quotient ${ }^{7}$. In our male patientbornwith increased birth weight, also have macrocephaly, low IQ \& h/o of developmental delay.

Other reported abnormalities include ocular abnormalities like strabismus, and deviation of one eye away fromother (exotropia), widely spaced eyes, visual impairment (amblyopia),abnormal elevation of optic disc which appears edematous (pseudopapilloedema). Patientsmay haveseizures \& thyroid problem $^{8-10}$. Skin abnormalities include presence of freckle-like pigmentedmacules on the penis in males or vulva in females ${ }^{11}$. Our patients may have coffeecolored spots on the skin (café-au-laitspots) or telangiectasias. In some cases, patients may present with musculoskeletal abnormalities like hypotonia, myopathy, hyperextensibility of joints, pectus excavatum, scoliosis and high arched palate.

The penile macules may present as small pigmentary changes that canbe missed during a cursory examination of the penis. It is morelikely to occur in later childhood, and its absence in infants and toddlers should not exclude consideration of the diagnosisof BRRS. Gontijo et al. 2013 reported BRRS with deforming lipomatous hamartomas in infant ${ }^{12}$. Intestinal hamartomatous polyposis occursin $35-45 \%$ of BRRS cases $^{13}$. The polyps may belocated along the entire gastrointestinal tract, more frequentlyin the colon and rectum. During infancy, theymay present with diarrhea, abdominal pain, painlessrectal bleeding, anemia, intussusception and intestinalobstruction. Our patient present with painless per rectal bleeding \& during colonoscopy polyp present in colon.

Marsh et al defined the clinical diagnosis of BRRS as the presence of three out of four feature: macrocephaly, lipomatosis, hemangiomas and speckled pigmented maculae on the penis ${ }^{14}$. Parisi et al defined the syndrome as the presence oftwo of the three feature: macrocephaly, hamartomas (including at least one lipoma, hemangioma or intestinal polyp) and maculae on the penis[15].In our case BRRS was diagnosed with the observation oftwo entities.
Patients with BRRS and Cowden have an increased risk for benign and malignant tumor formation.So,individuals with BRRS and a germline $P T E N$ pathogenic variant should undergo the same surveillance as individuals with Cowden syndrome.

\section{Acknowledgements:}

Dr. Bishnu Pada Dey, Medical Officer, Dept. of Pathology, BSMMU, Dhaka who provide the histopathological report of the patient.

\section{References:}

1. Lynch NE, Lynch SA, McMenamin J, Webb D. Bannayan-Riley-Ruvalcaba syndrome: a cause of extrememacrocephaly and neurodevelopmental delay. Arch Dis Child. 2009; 94:553-4.

2. Blumenthal GM, Dennis PA. PTEN hamartoma tumor syndromes. Eur J Hum Genet. 2008; 16:1289-300

3. Marsh DJ, Kum JB, Lunetta KL, Bennett MJ, Gorlin RJ, Ahmed SF, et al. Mutation spectrum and genotype phenotype analysis in Cowdens disease and Bannyan-Zonana syndrome, two hamartoma syndromes with germline PTEN mutation. Hum Mol Genet 1998; 7:507-15.

4. Bannayan G A. Lipomatosis, angiomatosis, and macrencephalia. A previously undescribed congenital syndrome.ArchPathol. 1971; 92 1-5

5. Orloff MS, Eng C. Genetic and phenotypic heterogeneity in the PTEN hamartoma tumour syndrome. Oncogene 2008; 27:5387-5397.

6. Latiff ZA, Atmawidjaja WR, Raje Lope JR, et al. Bannayan Riley Ruvalcaba syndrome. Ann Ajad Med Singapore 2010; 39:578.

7. Cohen M M. Mental deficiency, alterations in performance and CNS abnormalities in overgrowth syndromes. Am J Med Genet. 2003; 117 49-56

8. Gorlin RJ, Cohen MM Jr, Condon LM, Burke BA. Bannyan-Relay-Ruvalcaba syndrome. Am J Med Genet1992; 44:307-14

9. Palencia R, Ardura J. Bannyan syndrome with intracranial arteriovenous malformations. An EspPediatr1986; 25:462-6.

10. Dvir M, Beer S, Aladjem M. Heredofamilial syndrome of mesodermal hemartomas, macrocephaly and pseudopapilledema Pediatrics 1988;81:287-90. 
11. Fargnoli M C, Orlow S J, Semel-Concepcion J. Clinicopathologic findings in the Bannayan Riley Ruvalcaba-Syndrome. Arch Dermatol. 1996; 132 1214-18.

12. Gontijo GM, Pinto CA, Rogatto SR, Cunha IW, AguiarS Jr, Alves CA. Bannayan-RileyRuvalcabasyndromewith deforming lipomatous hamartomas in infant-case report. An Bras Dermatol2013; 88:982-5

13. Hilhorst $Y$, Hoefsloot $L$, Hansson $K B$, van der Straaten PJ, Boutkan $\mathrm{H}$, Breuning $\mathrm{MH}$, Vasen $\mathrm{HF}$, Bröcker-Vriends AH. Bannayan-RileyRuvalcaba syndrome: further delineation of the phenotype and management of PTEN mutationpositive cases. Fam Cancer 2003; 2:79-85.

14. Marsh DJ, Coulon V, Lunetta KL, Rocca-Serra P, Dahia PL, Zheng Z, et al. Mutation spectrum and genotype- phenotype analyses in Cowden disease and Bannayan-Zonana syndrome, two hamartoma syndromeswith germline PTEN mutation. Hum Mol Genet 1998; 7:507-15.

15. Parisi MA, Dinulos MB, Leppig KA, Sybert VP, Eng $C$, Hudgins $L$. The spectrum and evolution of phenotypic findings in PTEN mutation positive cases of Bannayan-Riley-Ruvalcaba syndrome. J Med Genet 2001; 38:52-8. 